\title{
The Tribofilm Formation of ZDDP Under Reciprocating Pure Sliding Conditions
}

\author{
Yasunori Shimizu $^{1,2} \cdot$ Hugh A. Spikes ${ }^{1}$
}

Received: 12 August 2016/Accepted: 17 October 2016/Published online: 2 November 2016

(c) The Author(s) 2016. This article is published with open access at Springerlink.com

\begin{abstract}
The anti-wear and anti-seizure performance and action mechanisms of zinc dithiophosphate (ZDDP) have been investigated under reciprocating pure sliding conditions to simulate piston ring and cylinder liner assembly, using new techniques. The Mini Traction Machine-Space Layer Imaging is a useful method for monitoring tribofilm formation by ZDDPs. However, tests are generally carried out in mixed sliding-rolling conditions and ZDDP film formation in reciprocating pure sliding conditions is rarely investigated. In this paper, the authors describe an investigation of ZDDP film formation in stationary ball on reciprocating disc pure sliding conditions and compare the results to those obtained in unidirectional pure sliding conditions. In unidirectional pure sliding conditions, the worn area on the ball expands with test time. By contrast, in reciprocating pure sliding conditions, tribofilm forms on the stationary ball and no significant damage occurs. In the initial tribofilm formation under reciprocating pure sliding conditions, solid particulate tribofilm with a high concentration of $\mathrm{S}$ forms initially in the contact area and subsequently breaks up. During further rubbing, a $\mathrm{Zn}$ - and P-rich tribofilm forms on the comminuted sulphur-rich tribofilm and also the area where the initial tribofilm was removed.
\end{abstract}

Yasunori Shimizu

yasunori.shimizu@idemitsu.com

1 Tribology Group, Department of Mechanical Engineering, Imperial College London, South Kensington, Exhibition Road, London SW7 2AZ, UK

2 Lubricants Research Laboratory, Idemitsu Kosan Co., Ltd, 24-4, Anesakikaigan, Ichihara-Shi, Chiba 299-0107, Japan
Keywords Zinc dithiophosphate - ZDDP · ZnDTP .

Tribofilm $\cdot$ Wear $\cdot$ Anti-wear $\cdot$ Pure sliding .

Reciprocating $\cdot$ MTM $\cdot$ SLIM

\section{Introduction}

As a consequence of the need to reduce the fuel consumption of passenger vehicles, the compression ratio and the specific power of internal combustion engines have been steadily increasing throughout the last 20 years $[1,2]$. Because of this, cylinder liner temperature near the combustion chamber, especially at top dead centre, has increased so the conditions have become more severe for wear and scuffing behaviour of piston ring cylinder liner contacts [3]. In these more severe conditions, engine oil formulations are required to maintain good anti-wear and anti-seizure performance. Since zinc dialkyldithiophosphates (ZDDPs) are widely used in engine oils, primarily as anti-wear additives, many researchers have studied their anti-wear and anti-seizure performance under reciprocating pure sliding conditions which simulate piston ring and cylinder liner assembly. In previous research, friction machines such as the Optimol SRV and Cameron Print reciprocating rig have been employed and tribofilms formed on the specimens after rubbing tests have been investigated [3-9]. Recently, a new approach to monitor ZDDP film formation process under pure sliding conditions using AFM (atomic force microscopy) was introduced by Gosvami et al. [10]. This method can track anti-wear film formation in situ at the nanometre level.

The Mini Traction Machine-Space Layer Imaging (MTM-SLIM, PCS Instrument) is also a well-known and useful method to monitor ZDDP tribofilm growth in situ, and its use to study the kinetics of ZDDP tribofilm growth has 
been widely reported [11-21]. In comparison with the new AFM technique, the MTM-SLIM method can observe a larger area and employ more flexible test conditions. In the past, MTM-SLIM has been generally carried out in mixed sliding-rolling conditions [11-20] and, very recently, in unidirectional pure sliding conditions [21]. ZDDP film formation in reciprocating pure sliding conditions has not yet been investigated using the MTM-SLIM method even though the behaviour of specimens in reciprocating conditions is likely to be different from that in unidirectional rolling conditions since mean speed and acceleration are continuously changing in reciprocating conditions, while these parameters are constant in unidirectional rolling conditions.

In this paper, ZDDP tribofilm formation is therefore monitored in reciprocating pure sliding conditions using MTM-SLIM.

\section{Test Methods}

The experiments in this work are conducted in a MTMSLIM ball on disc test rig as shown in Fig. 1a. In the normal operation of this rig, a 19.05-mm-diameter ball made of AISI $52100(\mathrm{Ra}=0.02 \mu \mathrm{m})$ is loaded against a flat surface of a 46-mm-diameter steel disc (AISI 52100, $\mathrm{Ra}=$ $0.01 \mu \mathrm{m})$ which is immersed in the oil sample. The ball and the disc are continuously driven by separate electric motors. At set intervals, motion is halted and the stationary ball is raised and loaded upward against a coated glass window

(a)
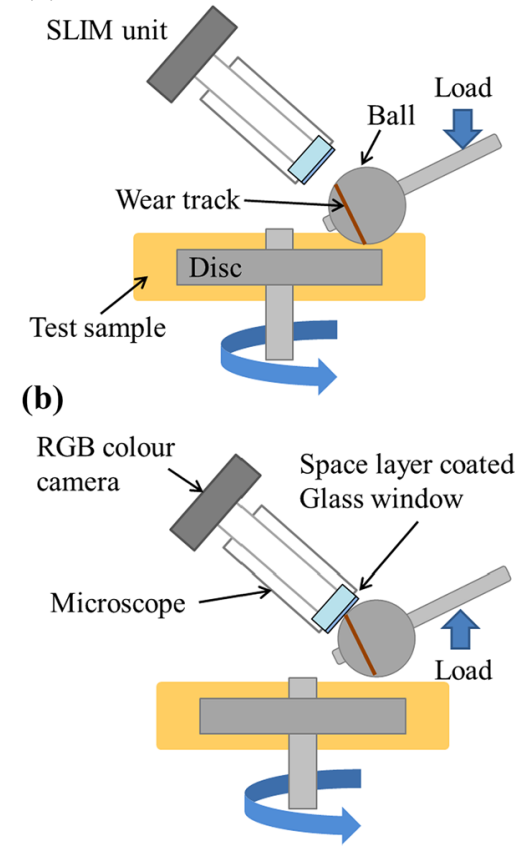

Fig. 1 a Schematic image of MTM-SLIM during a friction test. b Schematic image of MTM-SLIM while capturing an image
(Fig. 1b). An interference image of the contact between the ball and the glass window is captured from a camera in order to record tribofilm formation on the ball.

When mixed sliding-rolling conditions are used and the ball rotates, a tribofilm forms all around the ball (and the disc). This means that when the ball is loaded against the SLIM window, part of the rubbed track is always pressed against this window (Fig. 2a). However, in a recent paper the authors describe a study of ZDDP film formation in pure sliding conditions with the disc rotating but the ball stationary [21]. In this case, tribofilm forms on the ball only at its point of contact with the disc because the ball is fixed (Fig. 2b). Therefore, in order to measure the tribofilm formed on the ball a procedure was developed in which the ball shaft was rotated by $180^{\circ}$ prior to image capture, as shown schematically in Fig. 2.

In this previous study, the disc was rotated continuously to give unidirectional pure sliding and this was compared with behaviour in mixed sliding-rolling [21]. The current paper describes the behaviour of ZDDP in reciprocating pure sliding. In this, the ball is held stationary, while the disc is reciprocated with a stroke length of $4 \mathrm{~mm}$. This behaviour is compared with ZDDP behaviour in unidirectional pure sliding and in mixed sliding-rolling. Table 1 shows the main test condition used. For most work, the load, disc frequency, stroke length, mean speed and the lubricant temperature were kept constant at $20 \mathrm{~N}$ (maximum Hertzian pressure $\left.P_{\max }=0.82 \mathrm{GPa}\right), 20 \mathrm{~Hz}, 4 \mathrm{~mm}$, $160 \mathrm{~mm} / \mathrm{s}$ and $130{ }^{\circ} \mathrm{C}$, respectively. However, the influence of load, disc frequency, stroke length and temperature were also investigated.

\section{Test Lubricant}

All lubricant test samples were solutions of a ZDDP in polyalphaolefin base oil at a concentration that corresponded to $0.08 \mathrm{wt} \%$ of phosphorus. No other additives

(a) Mixed Sliding-Rolling conditions

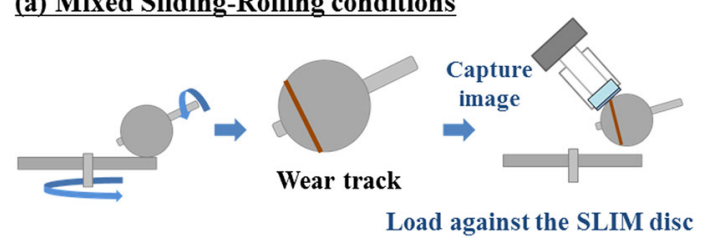

(b) Pure Sliding conditions

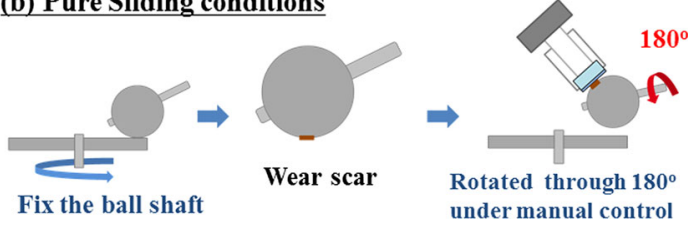

Fig. 2 Difference in the test methods between mixed sliding-rolling and pure sliding conditions [21] 
Table 1 Standard test condition under pure sliding reciprocating condition

\begin{tabular}{ll}
\hline Load $(N)$ & $20\left(P_{\max }=0.82 \mathrm{GPa}\right)$ \\
Ball speed $(\mathrm{mm} / \mathrm{s})$ & 0 \\
Disc frequency $(\mathrm{Hz})$ & 20 \\
Stroke length $(\mathrm{mm})$ & 4 \\
Average disc speed $(\mathrm{mm} / \mathrm{s})$ & 160 \\
Temperature $\left({ }^{\circ} \mathrm{C}\right)$ & Always 130 \\
\hline
\end{tabular}

were present. The ZDDP employed was a C8 primary type, and the base oil had a kinetic viscosity of $4.1 \mathrm{~mm}^{2} / \mathrm{s}$ at $100{ }^{\circ} \mathrm{C}, 2.6 \mathrm{~mm}^{2} / \mathrm{s}$ at $130{ }^{\circ} \mathrm{C}$ and a viscosity index of 124 .

\section{Test Results}

\subsection{Influence of Disc Movement}

In pure sliding reciprocating conditions, the disc is reciprocating and the ball is stationary. Therefore, tribofilm forms only on a point area on the ball as shown in the SLIM image in Fig. 3. In this and subsequent images, the reciprocating direction is horizontal (Fig. 3). In this figure, the diameter of the rubbing contact region on the ball (ca $216 \mu \mathrm{m}$ ) considerably smaller than the diameter of the Hertzian contact formed between the steel ball and the glass window (ca $272 \mu \mathrm{m}$ ) so the rubbed region lies fully within the SLIM image.

Figure 4 compares the results for tests performed under unidirectional and pure sliding reciprocating conditions. The load and temperature are listed in Table 1, while in unidirectional sliding the continuous disc speed was $160 \mathrm{~mm} / \mathrm{s}$ and thus the same as the mean reciprocating disc speed. It can be seen that the contact behaviours are very different in the two types of rubbing. In continuous sliding, the contact region grows rapidly, indicating a large amount of wear (although, as shown in Fig. 13 [21], some ZDDP tribofilm still forms). By contrast, in reciprocating conditions the rubbed area remains almost constant indicating no significant wear of the ball. After 1 min of sliding, initial tribofilm forms near the edges of the contact, but less tribofilm forms in the central region. Later in the test, tribofilm develops to cover the whole rubbing area.

Fig. 3 Reciprocating direction in SLIM images

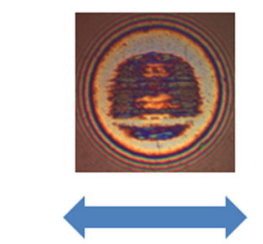

Reciprocating directions

\subsection{Effect of Load}

Pure sliding reciprocating tests were carried at the conditions listed in Table 1 but at four different applied loads $(5,10,15$ and $20 \mathrm{~N}$, corresponding to $P_{\max }=0.52,0.65,0.75$ and $0.82 \mathrm{GPa}$ ). Figure 5 shows the resultant SLIM images of the ball contact. Tribofilms start forming within $30 \mathrm{~s}$ from the beginning of the test over a set area that depends on the load. The film then thickens to cover this area. There appears to be no significant influence of load on the tribofilm forming process, and no surface damage was observed on the balls under any of these conditions. The areas of tribofilms were different at various load conditions because the theoretically calculated Hertz diameter areas were different. However, in each load condition, the diameter of tribofilms was close to the theoretically calculated Hertz diameter $(134,170,194$ and $216 \mu \mathrm{m}$ for the four loads, respectively). For the results at $60 \mathrm{~min}$ under $20 \mathrm{~N}$, the diameter of worn area was approximately $0.22 \mathrm{~mm}$ which corresponds closely to the theoretically calculated Hertz diameter.

For the results after $60 \mathrm{~min}$ from the beginning of the tests, the tribofilm regions have elliptical shape, being slightly longer in the reciprocating direction than transverse to this. One possible reason for this may be that the tribofilms are swept to the front and rear of the reciprocating directions and accumulate in these locations.

\subsection{Effect of Test Duration}

In the results in Fig. 5, it can be seen that separate tribofilms are formed initially near the front and rear of the contact area. In order to investigate this initial tribofilm formation further, SLIM images were captured every $5 \mathrm{~s}$ until $100 \mathrm{~s}$ for two repeat tests at $20 \mathrm{~N}$ load (Fig. 6). The speeds of tribofilm growth are somewhat different, but both tests show the same tribofilm formation process. In the first $5 \mathrm{~s}$, an initial tribofilm is created in the centre of the contact, having elliptical shape oriented with the long axis transverse to the sliding direction. After 10-s rubbing, the tribofilm patch becomes practically circular. On further rubbing, this tribofilm then separates into two regions near the front and rear of the contact, before eventually reforming from the top and bottom between these two regions to form a complete film.

\subsection{Effect of Speed}

Figure 7 shows the results for reciprocating tests performed at $5,10,15$ and $20 \mathrm{~Hz}$ and thus at different mean rubbing speeds (Table 2). The rate of tribofilm formation was slower when the frequency was decreased, but the overall process of tribofilm growth was the same. After $30 \mathrm{~s}$ at 5 and $10 \mathrm{~Hz}$, initial tribofilms were created in the centre of 
Fig. 4 Comparison of SLIM images of the wear scar on the ball under different disc movements

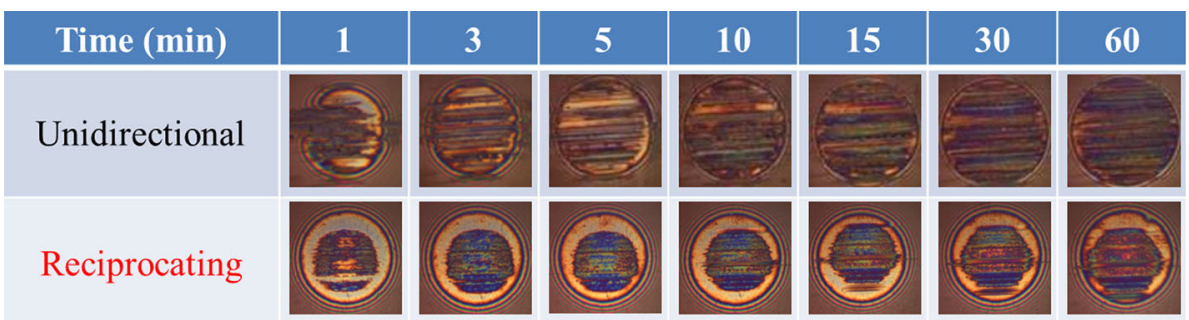
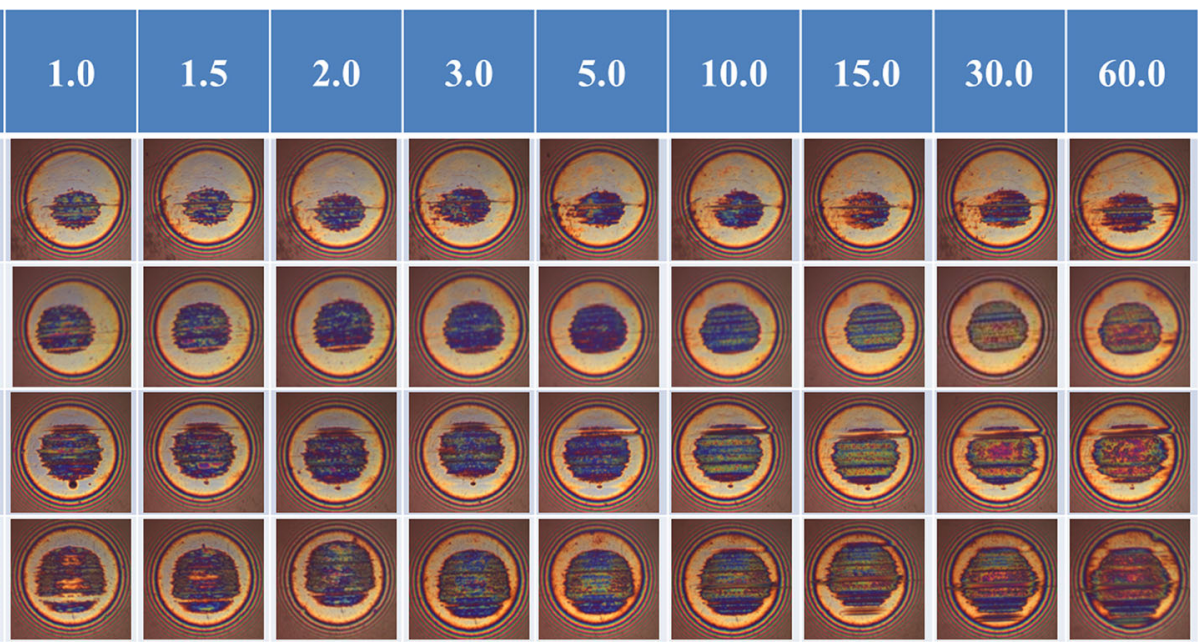

Fig. 5 Series of SLIM images of the ball in pure sliding reciprocating at various loads

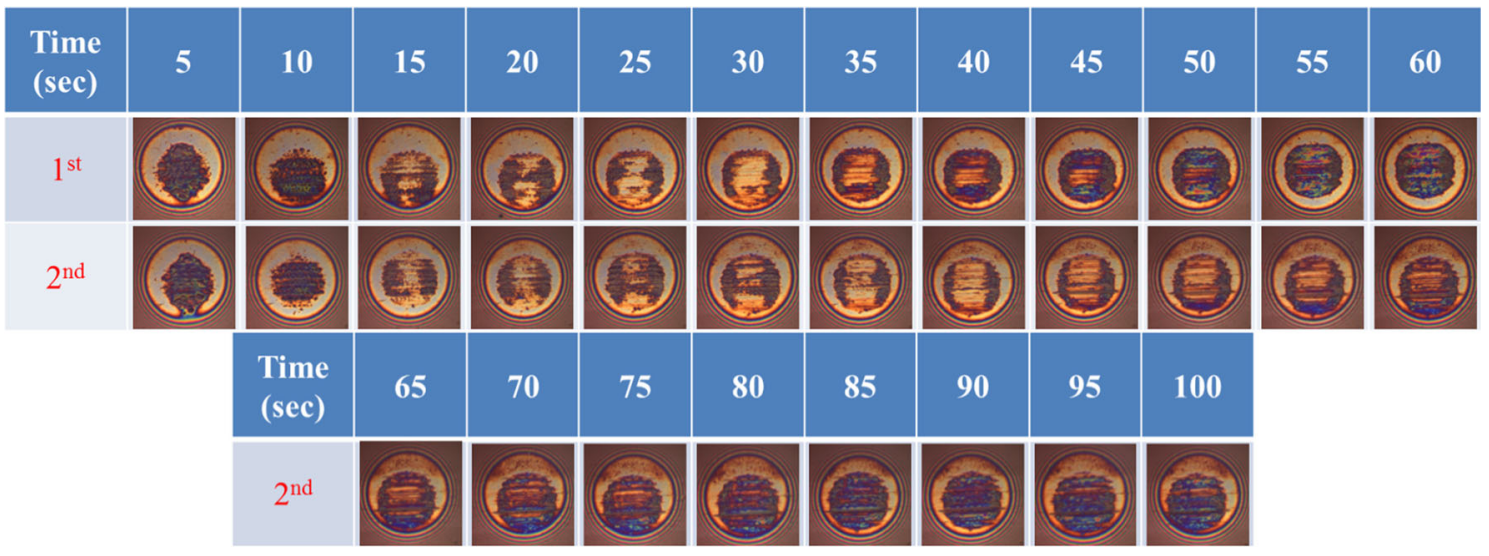

Fig. 6 Series of SLIM images of the ball at the initial stage

the contact area. After $1 \mathrm{~min}$ at 5 and $10 \mathrm{~Hz}$, but after $30 \mathrm{~s}$ at 15 and $20 \mathrm{~Hz}$, two tribofilms formed near the edges of the contact area. These film regions joined together after a time that decreased with increasing reciprocating frequency. After $60 \mathrm{~min}$, the tribofilms were continuous and elliptical at all frequencies.

\subsection{Effect of Stroke Length}

Figure 8 shows the results of tests performed using 4,8 and $16 \mathrm{~mm}$ stroke lengths, all at $10 \mathrm{~Hz}$, as well as one 4-mm- stroke-length test performed at $20 \mathrm{~Hz}$ (Table 3). The latter has the same average speed as the $8-\mathrm{mm} / 10-\mathrm{Hz}$ test. For the 4-mm-stroke-length/10-Hz test, the sizes of the two regions near the edges at $1 \mathrm{~min}$ were similar to the ones obtained at $30 \mathrm{~s}$ at $4-\mathrm{mm} / 20-\mathrm{Hz}$ conditions. For the tests carried out using 8 and $16 \mathrm{~mm}$ stroke lengths, the sizes of the edge regions were smaller than the ones obtained employing a $4 \mathrm{~mm}$ stroke length. In addition, there was no significant influence of stroke length on the rate of tribofilm formation although the sliding distance was increased by changing the length. One explanation may be that the 


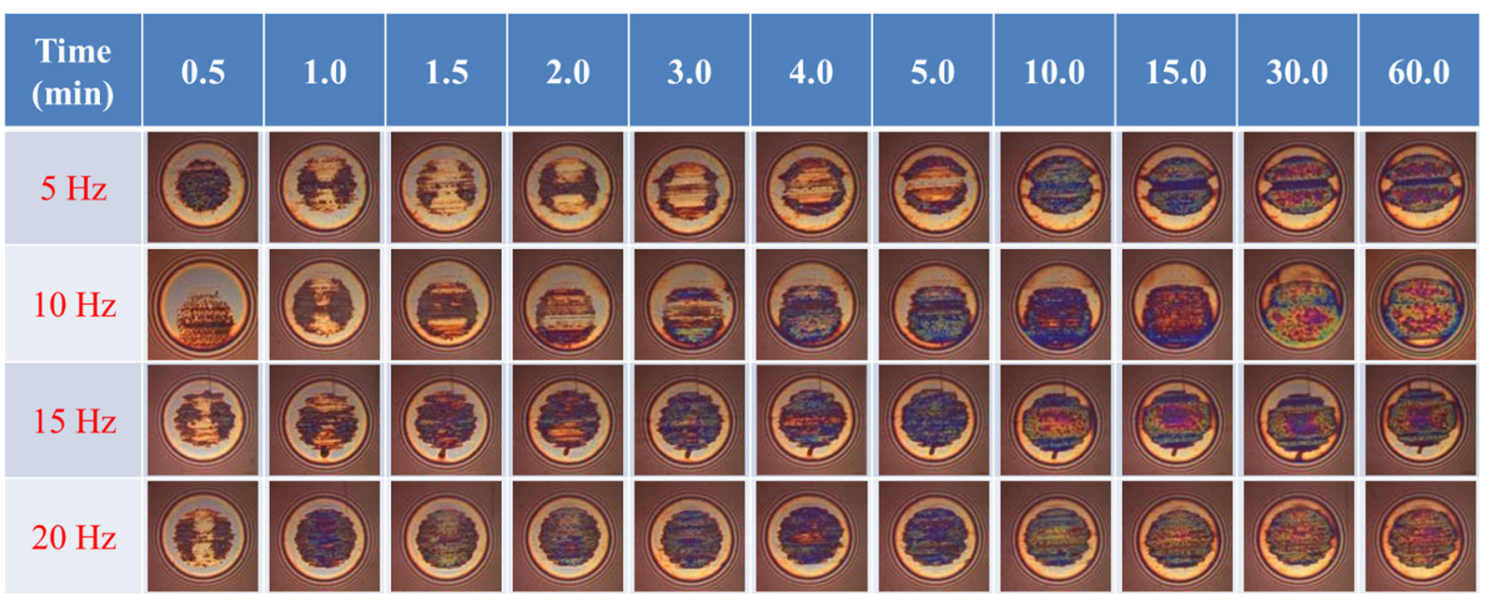

Fig. 7 Series of SLIM images of the ball at various disc frequencies

Table 2 Test conditions for disc frequency effect

\begin{tabular}{|c|c|c|c|}
\hline Load $(N)$ & \multicolumn{3}{|c|}{$20\left(P_{\max }=0.82 \mathrm{GPa}\right)$} \\
\hline SRR $(\%)$ & \multicolumn{3}{|l|}{200} \\
\hline Ball speed (mm/s) & \multicolumn{3}{|l|}{0} \\
\hline Disc frequency $(\mathrm{Hz})$ & 10 & 15 & 20 \\
\hline Stroke length (mm) & \multicolumn{3}{|l|}{4} \\
\hline Average disc speed $(\mathrm{mm} / \mathrm{s})$ & 40 & 120 & 160 \\
\hline Temperature $\left({ }^{\circ} \mathrm{C}\right)$ & \multicolumn{3}{|l|}{ Always 130} \\
\hline
\end{tabular}

lubrication regime shifted to higher lambda ratio conditions, less effective for building up ZDDP tribofilm, as the average and maximum speeds increased. However, although the sliding speeds at $10 \mathrm{~Hz}$ and $8 \mathrm{~mm}$ stroke are the same as at $20 \mathrm{~Hz}$ and $4 \mathrm{~mm}$ stroke, the tribofilm formation showed different processes under these two sets of conditions. This suggests that not only the speed but also stroke length affects tribofilm formation.
Table 3 Test conditions for stroke length effect

\begin{tabular}{|c|c|c|c|c|}
\hline Load $(N)$ & \multicolumn{4}{|c|}{$20\left(P_{\max }=0.82 \mathrm{GPa}\right)$} \\
\hline $\operatorname{SRR}(\%)$ & \multicolumn{4}{|l|}{200} \\
\hline Ball speed $(\mathrm{mm} / \mathrm{s})$ & \multicolumn{4}{|l|}{0} \\
\hline Disc frequency $(\mathrm{Hz})$ & \multicolumn{3}{|l|}{10} & 20 \\
\hline Stroke length (mm) & 4 & 8 & 16 & 4 \\
\hline Average disc speed $(\mathrm{mm} / \mathrm{s})$ & 80 & 160 & 320 & 160 \\
\hline Temperature $\left({ }^{\circ} \mathrm{C}\right)$ & \multicolumn{4}{|c|}{ Always 130} \\
\hline
\end{tabular}

\subsection{SEM-EDX Results}

Scanning electric microscope-energy-dispersive X-ray spectroscopy (SEM-EDX) was used to study some of the tribofilms formed on the ball in pure sliding reciprocating tests. A SEM, HITACHI S-3400N, was used to capture high-resolution images of tribofilm surface topography, and EDX, an Oxford X-ray System INCA, was used to

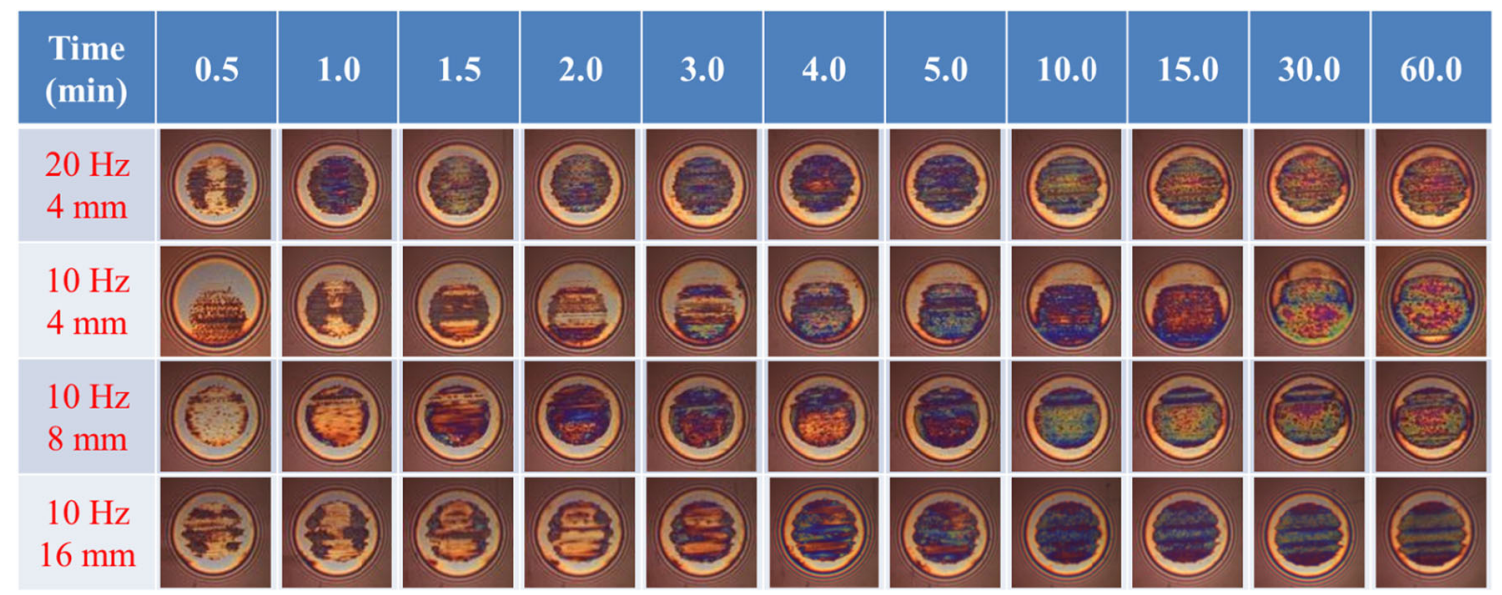

Fig. 8 Series of SLIM images of the ball at various stroke lengths 
analyse the chemical properties of tribofilms. In this study, the working distance was $10 \mathrm{~mm} \pm 1 \mathrm{~mm}$ and the accelerating voltage was 10 or $15 \mathrm{keV}$; from these voltages, it can be estimated that the beam enables the detection of chemical information about 1 micron depth into the samples. Six test specimens were prepared under different test conditions. All rubbing tests except image (d) were carried out at the conditions listed in Table 1 but at different test duration in order to obtain the samples at the different stages of tribofilm formation. The image (d) was tested under $4 \mathrm{~mm}$ stroke length/10 Hz. For the images (a) and (b) in Fig. 9, the test was stopped after $5 \mathrm{~s}$ and $20 \mathrm{~s}$, before the initial film separated into front and rear film regions. For the images (c) and (d), the test was halted after this separation (30, $60 \mathrm{~s}$ under $10 \mathrm{~Hz})$. For (e) and (f) images, tests were stopped after the separate regions of the tribofilm in the front and rear started to join together $(60 \mathrm{~s}, 30 \mathrm{~min})$.

From the SEM images, individual solid particles can be seen clearly in the images (a)-(d), which were captured before the tribofilm reformation started. In images (e) and (f), a pasty substance is observed. From the SEM-EDX analysis in Fig. 10, it can be seen that for the first four images $\mathrm{S}$ intensity is stronger than those of $\mathrm{P}$ and $\mathrm{Zn}$. However, when analysing the remaining two images, it is observed that the ratio of intensities changes and the $\mathrm{Zn}$ shows the strongest intensity.

Supporting evidence of these changes of intensities was obtained using the EDX mapping technique (Fig. 11). In the first 4 images, when the tests were stopped before the tribofilm reformed, the $\mathrm{S}$ intensity was stronger than the others and $\mathrm{S}, \mathrm{P}$ and $\mathrm{Zn}$ were observed only where there were solid particles. After the film started to reform, the $\mathrm{Zn}$ signal was strongest and the darker area in the SEM image showed $\mathrm{Zn}$ most strongly.
From these results, it can be concluded that two different types of tribofilm are created, displaying different properties depending on whether they are examined before and after the occurrence of film reformation. In other word, S-rich tribofilm is mainly created on steel ball surface, and then, P- and Zn-rich tribofilms replace and/or cover the S-rich tribofilm.

\subsection{AFM Results}

In order to study the tribofilm thickness of ZDDP films, AFM was used to analyse the MTM ball surface over the same area as the chemical analysis using SEM-EDX. In this study, the apparatus was a WITec alpha 300A and the cantilever was a WITec AFM Arrow Cantilever ReflexCoated. Results are shown in Fig. 12. At $5 \mathrm{~s}$ after the test started at $130{ }^{\circ} \mathrm{C}$, the tribofilm regions were up to $700 \mathrm{~nm}$ in height and $16 \mu \mathrm{m}$ in width. Before tribofilm separated (20 s), its height did not change significantly; however, the tribofilm area expanded to $60 \mu \mathrm{m}$. Shortly before the separation into front and rear regions (30 s), the tribofilm particles broke up into smaller sized ones, $350 \mathrm{~nm}$ in height and $10 \mu \mathrm{m}$ in width. After the onset of reformation, the height of tribofilm reached $130 \mathrm{~nm}$.

Since the initial particles before the separation showed strong $\mathrm{S}$ intensity and also the reformed tribofilms showed strong Zn and P intensity in Fig. 10, it can be concluded that the particles are sulphur rich, while the final film formed is ZDDP tribofilm. This sequence of sulphide followed by phosphate is in accord with the HSAB principle [21, 22]; however, the morphological changes are characteristic of pure sliding reciprocating conditions; the particulate tribofilm grows very rapidly but then breaks up and is swept to the front and rear of the reciprocating (a) $5 \mathrm{sec}$

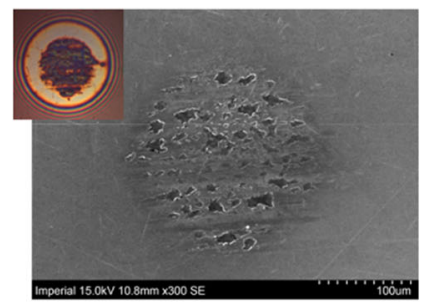

(d) $60 \mathrm{sec}, 10 \mathrm{~Hz}$

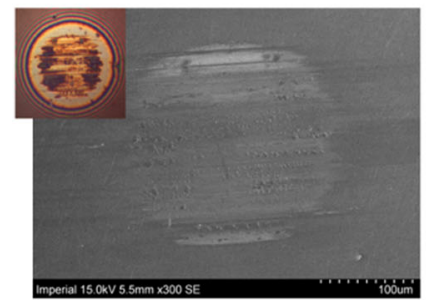

(b) $20 \mathrm{sec}$

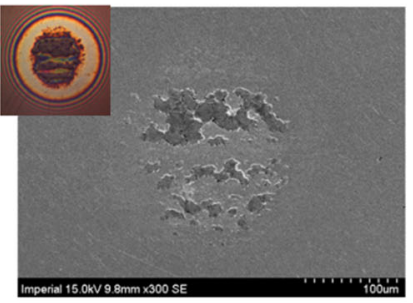

(e) $60 \mathrm{sec}$

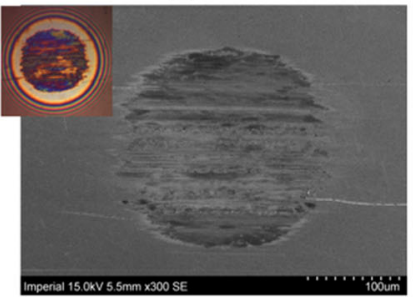

(c) $30 \mathrm{sec}$

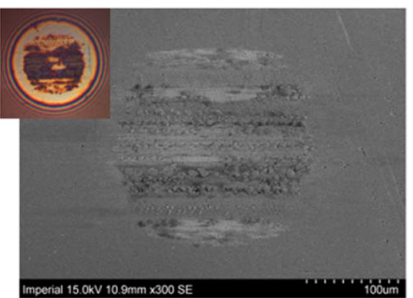

(f) $30 \mathrm{~min}$

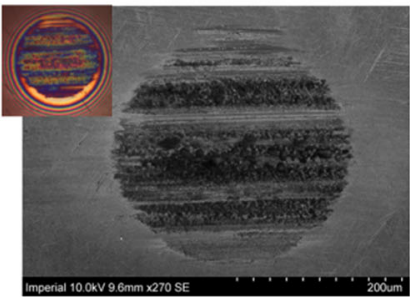

Fig. 9 SEM images obtained under various test conditions 


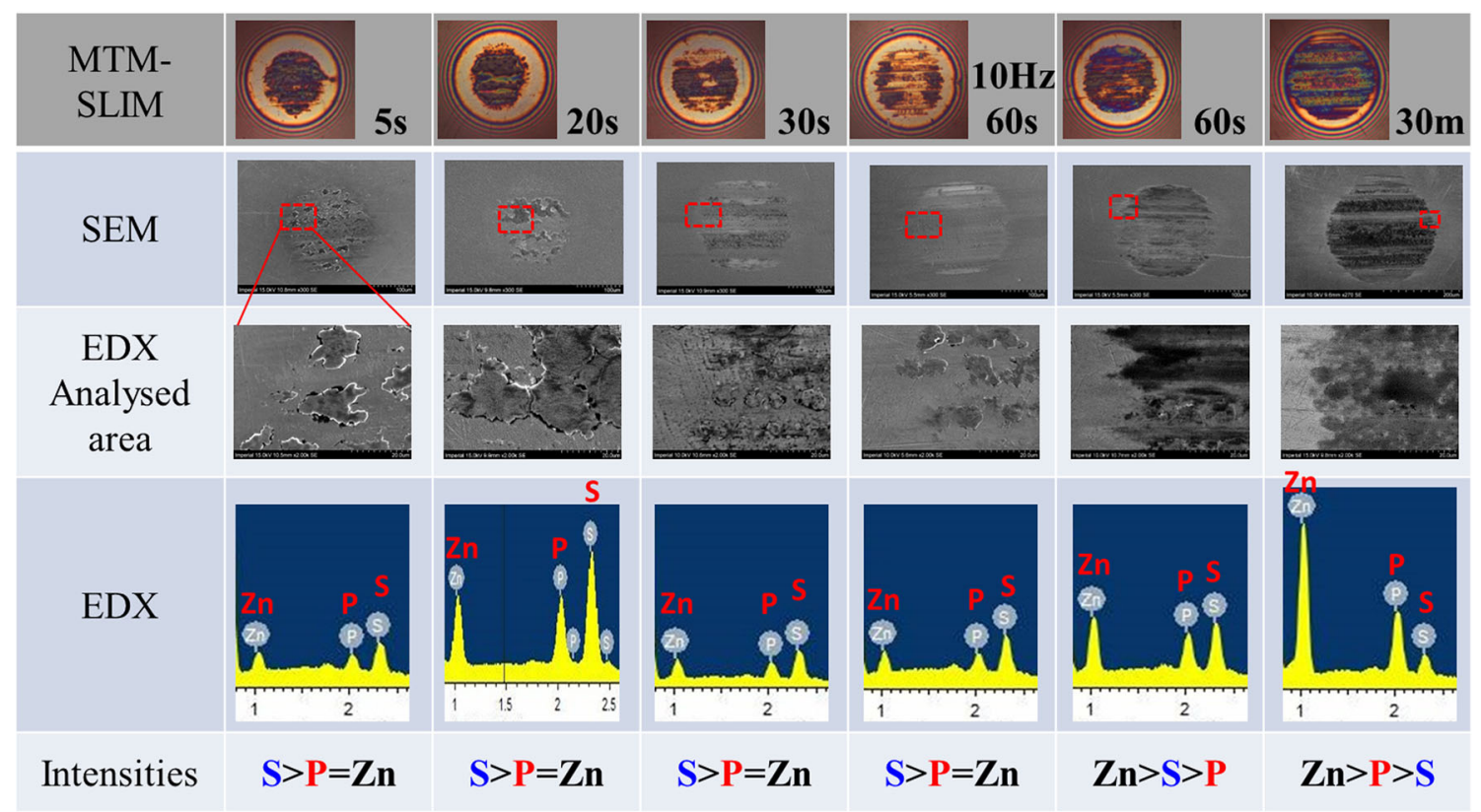

Fig. 10 Intensity results of elements using SEM-EDX

directions. During further rubbing, a $\mathrm{Zn}$ - and P-rich tribofilm forms on the comminuted sulphur-rich tribofilm and also the area where the initial tribofilm was removed.

\subsection{Comparison with Results in Unidirectional Pure Sliding Conditions}

It is of interest to compare the behaviour seen in reciprocating sliding with that seen and reported previously in unidirectional sliding conditions [23]. As shown in Fig. 4, in unidirectional conditions, the worn area on the stationary ball surface expands with time, whereas no significant damage is observed in pure sliding reciprocating conditions. From the previous research by the authors (Figs. 13, 14) in [23], in the unidirectional pure sliding conditions shown in Fig. 4, after $30 \mathrm{~s}$ from the beginning of the test, 550-nm-thick particles were observed on the ball with strong $\mathrm{S}$ intensity in EDX analysis, but after further rubbing, a film with a high concentration of $\mathrm{Zn}$ and $\mathrm{P}$ was formed. The sequence of tribofilm formation thus shows similarities between unidirectional and reciprocating conditions, even though wear is observed only in unidirectional pure sliding conditions.

It is not clear why the wear behaviour is so different in unidirectional and reciprocating conditions, but this may relate to whether and to what extent a tribofilm forms on the moving disc surface, which may depend on the proportion of time that any part of the disc is in contact. In explore this, tribofilms on the disc were also analysed using SEM-EDX. Five discs were prepared under different test conditions: two discs after 30- and 60-s unidirectional tests with the same test conditions as those in Fig. 13, two discs from reciprocating tests after 5 and $30 \mathrm{~s}$ as shown in Fig. 9 and the last disc from a 10-Hz, 16-mm-stroke-length 120-s test as shown in Fig. 8.

From SEM results at $30 \mathrm{~s}$ in unidirectional conditions and 5 and $30 \mathrm{~s}$ in reciprocating condition, unlike on the ball, no particles were found on the disc (Fig. 15). Therefore, it can be said that the very thick sulphur-rich particulate tribofilm forms only on the stationary surface. For the EDX results, the intensities of $\mathrm{Z}, \mathrm{P}$ and $\mathrm{S}$ were compared to that of carbon in the disc material AISI 52100. After $30 \mathrm{~s}$ in unidirectional pure sliding, $\mathrm{Zn}, \mathrm{P}$ and $\mathrm{S}$ were observed, but after $60 \mathrm{~s}$, the intensity of all three of these peaks diminished. This indicates that in unidirectional sliding, some tribofilm forms on the disc surface initially, but this is removed as further wear occurs. By contrast, in reciprocating tests after 5 and $30 \mathrm{~s}$ the intensities of $\mathrm{Zn}, \mathrm{P}$ and $\mathrm{S}$ became stronger with rubbing time although the initial sulphur-rich tribofilms on the ball were removed. The film present after $120 \mathrm{~s}$ at $16 \mathrm{~mm} / 10 \mathrm{~Hz}$ was similar, and comparison of the 4- and 16- $\mathrm{mm}$ tests indicated no significant influence of stroke length on tribofilm on the disc. Since the sliding length per one cycle in unidirectional sliding is about $132 \mathrm{~mm}$, this length is still much longer than the $16 \mathrm{~mm}$ stroke length and it is possible that this limits the ability of a tribofilm to form on the disc surface.

As a final confirmation of the importance of a tribofilm forming on the disc surface, one additional unidirectional test was carried out using a new ball and a used disc covered with ca. $45 \mathrm{~nm}$ of ZDDP tribofilm. In order to prepare this used disc, a mixed sliding-rolling test was 


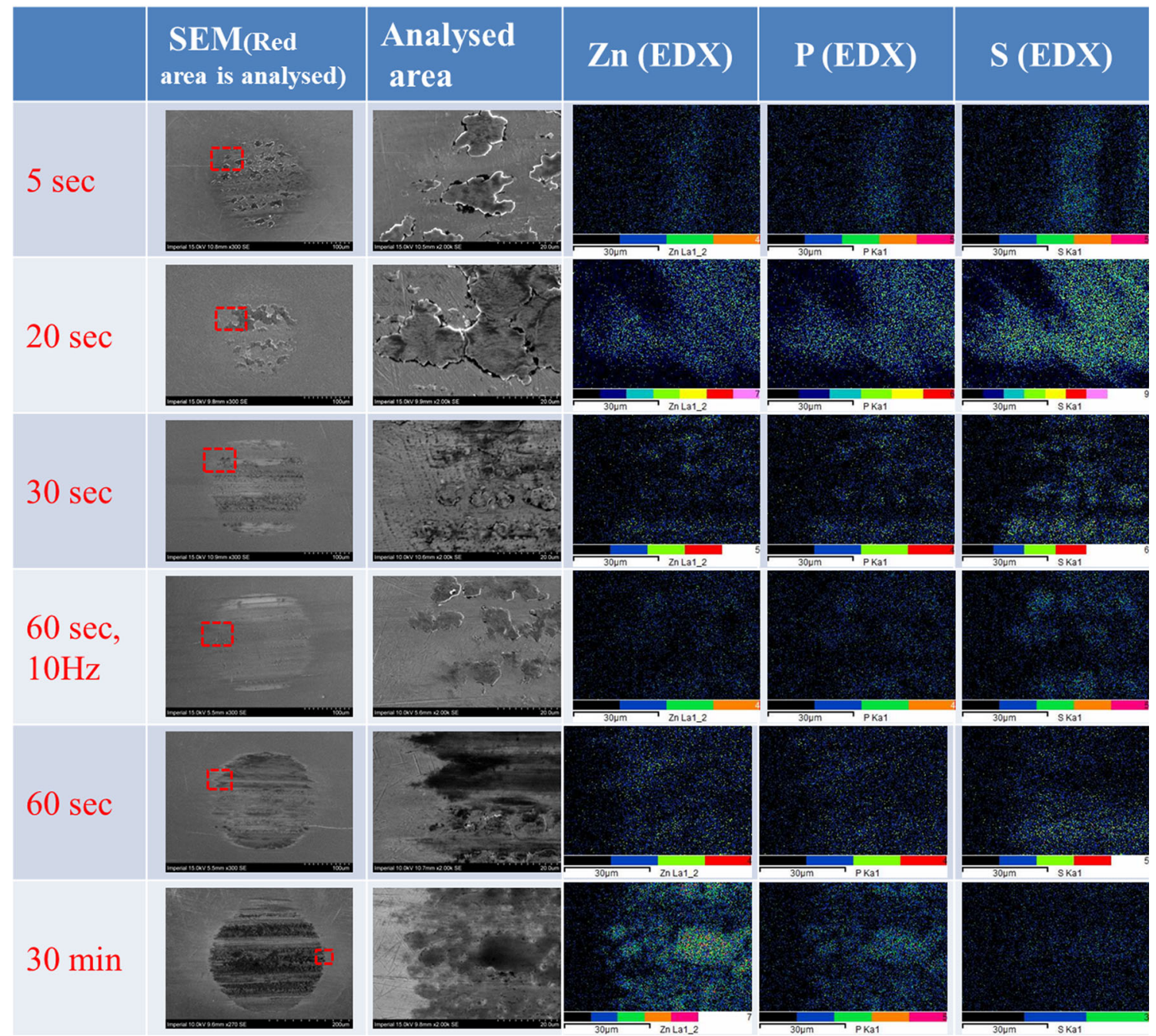

Fig. 11 Mapping results of elements as obtained using SEM-EDX

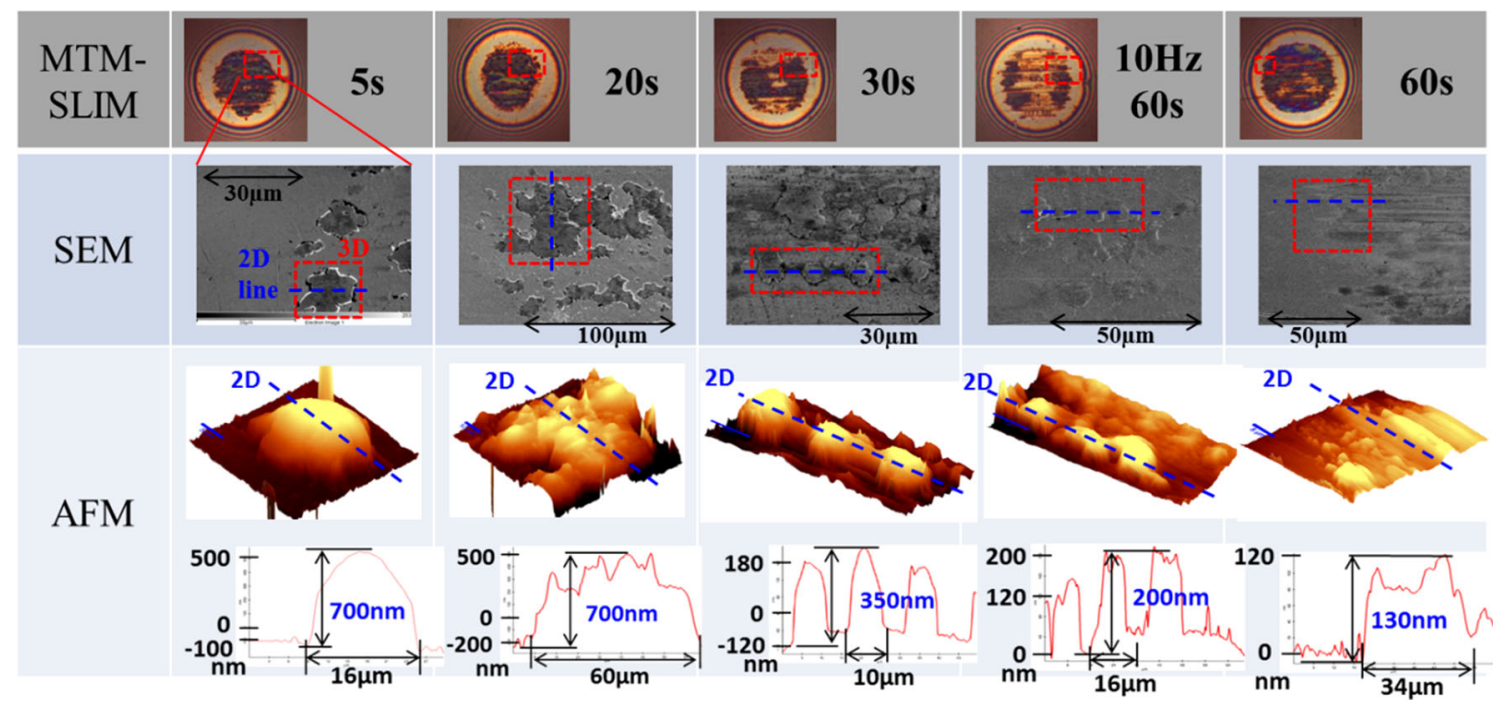

Fig. 12 Film thicknesses as obtained using AFM 


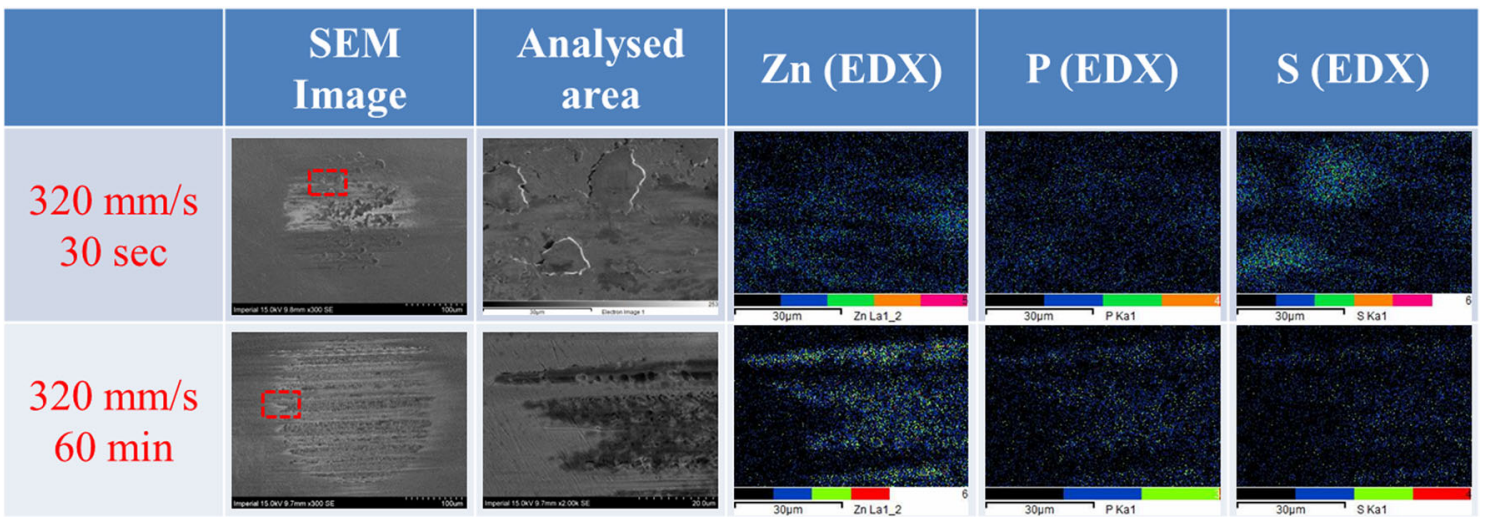

Fig. 13 Mapping results of elements as obtained using SEM-EDX under unidirectional pure sliding condition

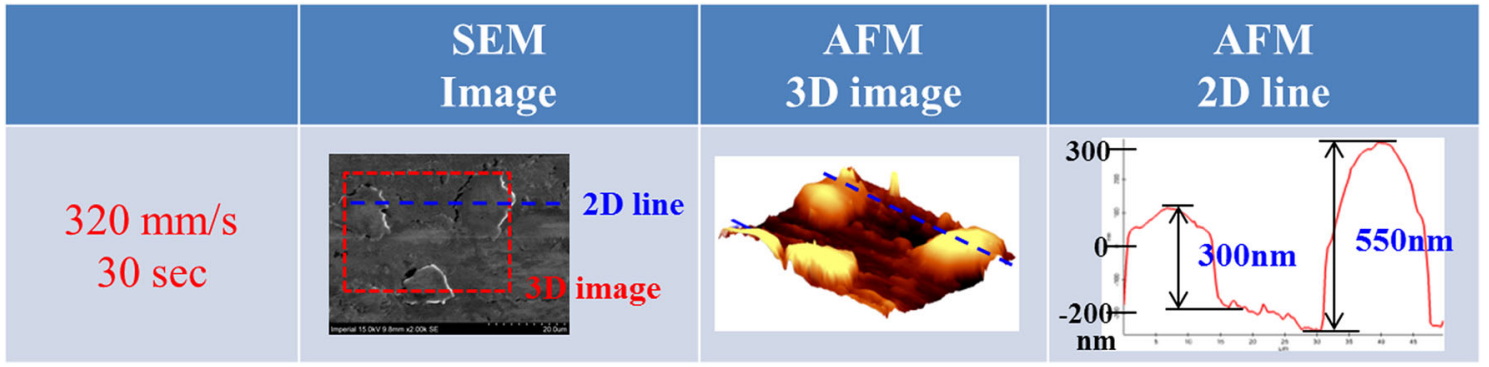

Fig. 14 Initial film thicknesses under unidirectional pure sliding condition

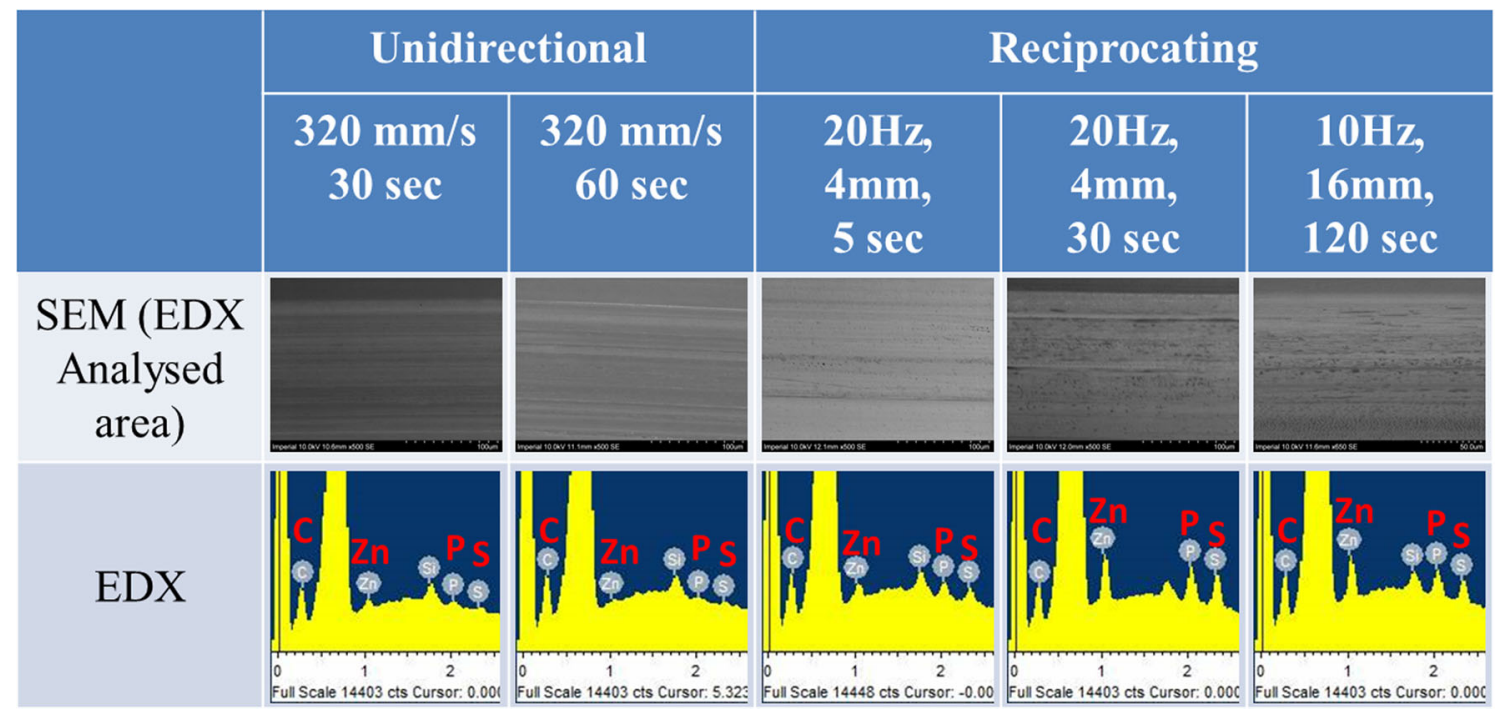

Fig. 15 Intensity results of elements using SEM-EDX on the disc

carried out under the following conditions: $20 \mathrm{~N}$ load, $50 \%$ slide roll ratio $(125 \mathrm{~mm} / \mathrm{s}$ in disc speed and $75 \mathrm{~mm} / \mathrm{s}$ in ball speed), $130{ }^{\circ} \mathrm{C}$ and $45 \mathrm{~min}$. The used disc was then left in place, but the used ball was replaced by a new ball, the used lubricant changed for a fresh sample, and a unidirectional pure sliding test was then carried out at $10 \mathrm{~N}$ load, $160 \mathrm{~mm} / \mathrm{s}$ disc speed and $130{ }^{\circ} \mathrm{C}$. The succession of
SLIM images obtained is shown in Fig. 16. At the beginning of the test, a build-up of tribofilm was observed in left side of the contact area on the ball. Since, in the SLIM images shown, lubricant enters the contact area from left side and leaves from the right side, this suggests that tribofilm from the used disc is transferred into the inlet of the contact area on the ball. From Fig. 16, it can be seen that 
Fig. 16 Series of SLIM images of the ball in unidirectional pure sliding using a new ball and a disc covered by $\mathrm{Zn}$ and $\mathrm{P}$ tribofilms

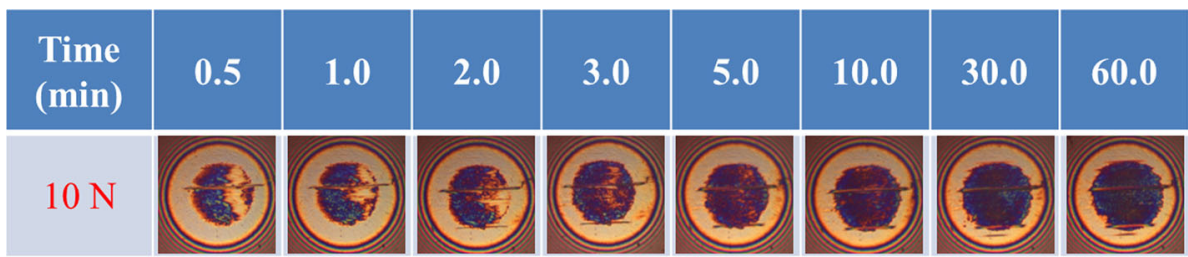

there was no significant wear of the ball during the test, unlike what was observed when a fresh ball is used as in Fig. 4.

This means that when a disc already covered by $\mathrm{Zn}$ and $\mathrm{P}$ tribofilm is used, no significant damage on the ball occurs even in unidirectional pure sliding condition. Therefore, $\mathrm{Zn}$ and $\mathrm{P}$ tribofilms can show good anti-wear performance in unidirectional pure sliding conditions only if enough tribofilm is built up before initial wear takes place. Thus, in unidirectional sliding wear takes place initially because the ZDDP film does not form fast enough on the ball. This suggests that initial $\mathrm{S}$ tribofilm has important role for protecting the steel surface from initial wear because $\mathrm{Zn}$ and $\mathrm{P}$ tribofilm formation takes a longer time to be built up than $\mathrm{S}$ tribofilm.

\subsection{Hypothesis of How Tribofilms Build Up on the Ball in Pure Sliding Reciprocating Conditions}

From this study, the following hypothesis of how tribofilms build up on the ball in pure sliding reciprocating conditions is suggested (Fig. 17). Firstly, high sulphur-content tribofilm material is built up in certain areas. Secondly, the size of the high sulphur-content tribofilm particles increases. Thirdly, these tribofilm particles break up into smaller fragments and move to the front and rear to form two distinct regions. Finally, $\mathrm{Zn}$ and $\mathrm{P}$ tribofilms are created, mainly between the two regions and on top of the initial sulphur particles. If insufficient tribofilm forms on the

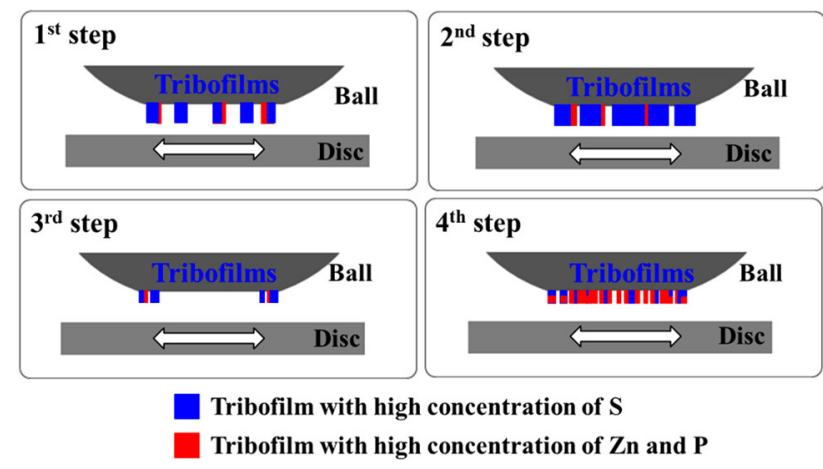

Fig. 17 Hypothesis of how tribofilms build up on the ball in pure sliding reciprocating conditions moving countersurface, possibly because this spends too high a proportion of the test time out of contact, then the high sulphur contest still forms on the ball, but the second, $\mathrm{Zn} / \mathrm{P}$ tribofilm formation on the ball is very slow and unable to prevent wear.

\section{Conclusion}

The authors have developed a new approach to study ZDDP tribofilm formation in pure sliding reciprocating conditions based on the MTM-SLIM method. Key conclusions are as follows.

1. In the unidirectional pure sliding condition, the worn area on the ball expands with test time, indicating considerable wear. By contrast to this, in the reciprocating pure sliding conditions, tribofilm forms on the ball and no significant damage occurs. In addition, there is no significant influence of load, disc frequency and stroke length on the tribofilm forming process and no surface damage occurs on the balls under any conditions tested.

2. In the initial tribofilm formation on the ball under reciprocating pure sliding conditions, solid particulate tribofilms with a high concentration of S form initially in the centre of the contact area. Subsequently, the tribofilm separates into two regions near the front and rear of the contact, before reforming a pasty tribofilm between these regions with a high concentration of $\mathrm{Zn}$ and $\mathrm{P}$.

3. In order to avoid any damage to the ball surface, it is essential to build up a ZDDP tribofilm on the disc; once tribofilm forms on the disc surface, no further significant damage on the ball surface occurs even if a new ball is employed.

In most previous research on ZDDP tribofilm formation, attention has focussed on the thick glassy Fe phosphate and $\mathrm{Zn}$ phosphate layers after rubbing test. This study has shown that in pure sliding reciprocating conditions, a sulphur-rich thicker tribofilm is initially formed and removed from the steel surface, and then, the phosphate-based layer develops. Such behaviour may suggest that sulphur content providing extreme pressure response has important role for protecting the steel surface from initial wear even though 
zinc and phosphorus tribofilms subsequently build up to provide prolonged anti-wear protection.

Open Access This article is distributed under the terms of the Creative Commons Attribution 4.0 International License (http://crea tivecommons.org/licenses/by/4.0/), which permits unrestricted use, distribution, and reproduction in any medium, provided you give appropriate credit to the original author(s) and the source, provide a link to the Creative Commons license, and indicate if changes were made.

\section{References}

1. Heywood, J.B., Welling, O.Z.: Trends in performance characteristics of modern automobile SI and diesel engines. SAE Int. J. Engines 2, 1650-1662 (2009)

2. Vora, K.C., Ramdasi, S.S., Walke, N.H., Marathe, A.W., Marathe, N.V.: Development strategy for high specific power low emission diesel engines. SAE Technical Paper, 2009-26-0020 (2009)

3. Obert, P., Müller, T., Füßer, H.J., Bartel, D.: The influence of oil supply and cylinder liner temperature on friction, wear and scuffing behavior of piston ring cylinder liner contacts-a new model test. Tribol. Int. 94, 306-314 (2016)

4. Minfray, C., Martin, J.M., De Barros, M.I., Mogne, T.L., Kersting, R., Hagenhoff, B.: Chemistry of ZDDP tribofilm by ToFSIMS. Tribol. Lett. 17, 351-357 (2004)

5. Martin, J.M., Grossiord, C., Mogne, T.L., Bec, S., Tonck, A.: The two-layer structure of Zndtp tribofilms: part I: AES, XPS and XANES analyses. Tribol. Int. 34, 523-530 (2001)

6. Varlot, K., Kasrai, M., Martin, J.M., Vacher, B., Bancroft, G.M., Yamaguchi, E.S., Ryason, P.R.: Antiwear film formation of neutral and basic ZDDP: influence of the reaction temperature and of the concentration. Tribol. Lett. 8, 9-16 (2000)

7. Zhang, Z., Yamaguchi, E.S., Kasrai, M., Bancroft, G.M., Liu, X., Fleet, M.E.: Tribofilms generated from ZDDP and DDP on steel surfaces: part 2, chemistry. Tribol. Lett. 19, 221-229 (2005)

8. Aktary, M., McDermott, M.T., McAlpine, G.A.: Morphology and nanomechanical properties of ZDDP antiwear films as a function of tribological contact time. Tribol. Lett. 12, 155-162 (2002)

9. Minfray, C., Martin, J.M., Esnouf, C., Le Mogne, T., Kersting, R., Hagenhoff, B.: A multi-technique approach of tribofilm characterisation. Thin Solid Films 447, 272-277 (2004)
10. Gosvami, N.N., Bares, J.A., Mangolini, F., Konicek, A.R., Yablon, D.G., Carpick, R.W.: Mechanisms of antiwear tribofilm growth revealed in situ by single-asperity sliding contacts. Science 348, 102-106 (2015)

11. Spikes, H.A., Cann, P.M.: The development and application of the spacer layer imaging method for measuring lubricant film thickness. Proc. Inst. Mech. Eng. Part J: J. Eng. Tribol. 215, 261-277 (2001)

12. Taylor, L., Dratva, A., Spikes, H.A.: Friction and wear behavior of Zinc dialkyldithiophosphate additive. Tribol. Trans. 43, 469-479 (2000)

13. Fujita, H., Spikes, H.A.: The formation of zinc dithiophosphate antiwear films. Proc. Inst. Mech. Eng. Part J: J. Eng. Tribol. 218, 265-278 (2004)

14. Fujita, H., Glovnea, R.P., Spikes, H.A.: Study of zinc dialkydithiophosphate antiwear film formation and removal processes, part I: experimental. Tribol. Trans. 48, 558-566 (2005)

15. Fujita, H., Spikes, H.A.: Study of zinc dialkyldithiophosphate antiwear film formation and removal processes, part II: kinetic model. Tribol. Trans. 48, 567-575 (2005)

16. Ksenija, T.M., Forbus, T.R., Spikes, H.A.: Film thickness and roughness of ZDDP antiwear films. Tribol. Lett. 26, 161-171 (2007)

17. Matthew, S., Hamer, C., Spikes, H.A.: A Study of Antiwear Additive Film Build Up Using the MTM (Mini-Traction Machine). In: ASME/STLE 2007 International Joint Tribology Conference. American Society of Mechanical Engineers (2007)

18. Miklozic, K.T., Forbus, T.R., Spikes, H.A.: Performance of friction modifiers on ZDDP generated surfaces. Tribol. Trans. 50, 328-335 (2007)

19. Olomolehin, Y., Kapadia, R., Spikes, H.: Antagonistic interaction of antiwear additives and carbon black. Tribol. Lett. 37, 49-58 (2010)

20. Zhang, J., Yamaguchi, E., Spikes, H.: The Antagonism between succinimide dispersants and a secondary zinc dialkyl dithiophosphate. Tribol. Trans. 57, 57-65 (2014)

21. Pearson, R.G.: Chemical Hardness. Wiley, New York (1996)

22. Martin, J.M.: Antiwear mechanisms of zinc dithiophosphate: a chemical hardness approach. Tribol. Lett. 6, 1-8 (1999)

23. Shimizu, Y., Spikes, H.A.: The influence of slide-roll ratio on ZDDP tribofilm formation. Tribol. Lett. 64, 19 (2016) 